\title{
Study of the Chemical Components, Bioactivity and Antifungal Properties of the Coffee Husk
}

\author{
Luigi Castaldo ${ }^{1}$, Giulia Graziani ${ }^{1}$, Anna Gaspari ${ }^{1}$, Luana Izzo $^{1}$, Carlos Luz $^{2}$, Jordi Mañes ${ }^{2}$, Mario Rubino ${ }^{3}$, \\ ${\text { Giuseppe } \text { Meca }^{2} \& \text { Alberto Ritieni }}^{1}$ \\ ${ }^{1}$ Department of Pharmacy, University of Naples "Federico II", Via D. Montesano 49, 80131 Napoli, Italy \\ ${ }^{2}$ Laboratory of Food Chemistry and Toxicology, Faculty of Pharmacy, University of Valencia, Av. Vicent Andrés \\ Estellés s/n, 46100 Burjassot, Spain \\ ${ }^{3}$ Interkom S.p.A, Via Gian Lorenzo Bernini 20, 80129 Napoli, Italy \\ Correspondence: Luigi Castaldo, Department of Pharmacy, Faculty of Pharmacy, University of Naples "Federico \\ II”, Via D. Montesano 49, 80131 Napoli, Italy. Tel: 390-8167-8116. E-mail: luigi.castaldo2@ unina.it
}

$\begin{array}{ll}\text { Received: February 23, } 2018 & \text { Accepted: March 14, } 2018 \quad \text { Online Published: May 23, } 2018 \\ \text { doi:10.5539/jfr.v7n4p43 } & \text { URL: https://doi.org/10.5539/jfr.v7n4p43 }\end{array}$

\begin{abstract}
Coffee husk is a fibrous mucilaginous material representing the major residues from the handling and processing of coffee. Currently, coffee husk is discarded which contributes to environmental pollution. Dry and semi-dry coffee husk were extracted by hot infusion and the polyphenol profile was studied by UHPLC and Q-Orbitrap mass spectrometry. Free radical scavenging activity in the infusion was between 26.61 at $31.33 \mathrm{mmol}$ Trolox equivalent antioxidant capacity (TEAC)/kg, as measured by the assay with ABTS and DPPH radical. The results indicated that coffee husk contained 367.45 and $396.04 \mathrm{~g} / \mathrm{kg}$ of total dietary fiber in dry and semi-dry sample, respectively. While the infusions contain exclusively soluble dietary fiber 0.64 and $0.98 \mathrm{~g} / \mathrm{L}$. The methanol extracts of coffee husk presented antimicrobial activity of P. camemberti, P. expansum and P. roqueforti, A. flavus and A. niger, many of their mycotoxins producers. The minimum inhibitory concentration (MIC) and minimum fungicidal concentration (MFC) values for the Penicilliums strains ranged from 6.3 to $50 \mathrm{~g} / \mathrm{L}$, whereas on the Aspergillus strains the data detected ranged from 25 to $50 \mathrm{~g} / \mathrm{L}$, respectively. This study indicates the possible exploiting of this coffee by-product as potential natural health promoting and preservative ingredient.
\end{abstract}

Keywords: bioactive compounds, polyphenol, antifungal properties, HRMS-Orbitrap

\section{Introduction}

Coffee is the most preferred morning beverage throughout the world due to its pleasant flavor and stimulating properties. In 2016, the total production of coffee was of 151.624 million of $60 \mathrm{~kg}$ bags, and the Brazil is largest producer (ICO, 2016); its production, indeed, causes the generetion of an enormous amount of wastes and by-product (Andrade et al., 2011). It was observed that coffee-derived wastes and by-products represent a source of serious contamination, in main coffee producer countries. Particularly, caffeine $(12 \mathrm{~g} / \mathrm{kg})$, tannins $(63 \mathrm{~g} / \mathrm{kg})$ and polyphenols (Franca, Gouvea, Torres, Oliveira, \& Oliveira, 2009; Rathinavelu \& Graziosi, 2005; Andrade et al., 2011), have been recognized the main substances involved in this environmental problem. (Franca, Gouvea, Torres, Oliveira, \& Oliveira, 2009; Rathinavelu \& Graziosi, 2005; Andrade et al., 2011),

Coffee husk is a fibrous mucilagenous material obtained during the processing of coffee cherries by dry and semi-dry process, respectively (Pandey et al., 2000). It is the main residue in the production of coffee and currently it was used especially in ruminant feed. Several studies, proposed coffee husk as silage, aerobic composting, animal feed, vermiculture, production of biogas, vinegar, biopesticides, enzymes, single-cell protein and probiotics (Fan, Soccol, Pandey, \& Soccol, 2003). However, this residue has low commercial use and it is returned to the soil or burned, could be a serious threat to environmental pollution.

Recently the use of by-products for further using as food additives on the production of natural food ingredients with high nutritional value have gained increasing interest because these are high-value products and their recovery may be economically attractive (Murthy \& Naidu, 2012a)

Coffee husks can be an innovative resource of phytochemicals for the food and pharmaceutical industries, because it contains high levels of compounds with antioxidant activity, caffeine and dietary fiber (Esquivel \& 
Jiménez, 2012; Mennini, 2013).

Furthermore caffeic and quinic acid derivatives showed a remarkable antifungal activity. In particular, recently was provide the evidence that caffeic and caffeolquinic acids are able to inhibit the fungal growth by blocking the glucan synthase in cell wall. (Ma \& Ma, 2015; Villarino, Sandín-Espana, Melgarejo, \& De Cal, 2011).

The objectives of this study were a) to investigate the qualitative and quantitative profile of the bioactive compounds in coffee husk (raw material and infusion) using UHPLC-High resolution mass spectrometry b) the antioxidant activity through the ABTS and DPPH assays c) Determination of Total, Soluble, and Insoluble Fiber and d) the antifungal activity in solid and liquid medium (MIC-MFC).

\section{Materials and Methods}

\subsection{Samples and Treatments}

Two types of coffee husk derived from coffee Arabica (coffee husk 1 and coffee husk 2) which will be called from now $\mathrm{CH} 1$ and $\mathrm{CH} 2$, were obtained from Café do Brasil S.p.A. (Naples, Italy). CH1 and CH2 were obtained by dry and semi-dry processing of coffee cherries, respectively. The procedure adopted for the preparation of coffee husk infusion (CHI) was as follows: $100 \mathrm{~mL}$ boiling water was poured onto $4 \mathrm{~g}$ of the coffee husk, covered and left to infuse for 4 min. After filtration with Whatman No. 1 paper, the volume and dry matter yield were measured. Subsequently, infusions were filtered through a $0.2 \mu \mathrm{m}$ nylon filter and immediately frozen and stored at $-18^{\circ} \mathrm{C}$ until analysis. For the preparation of coffee husk polyphenol extract (CHPE), each sample was weighed $(0.5 \mathrm{~g})$, reduced to a fine powder in a blender and extracted with $25 \mathrm{~mL}$ of $\mathrm{CH}_{3} \mathrm{OH}: \mathrm{H}_{2} \mathrm{O}(80: 20 \mathrm{v} / \mathrm{v})$ by vortexing for $2 \mathrm{~min}$ followed by $10 \mathrm{~min}$ in an ultrasonic bath and $20 \mathrm{~min}$ on an horizontal shaker at $250 \mathrm{rpm}$. The solution was centrifuged at $4500 \mathrm{~g}$ for $5 \mathrm{~min}$ and the supernatant was transferred to a $50 \mathrm{~mL}$ tube and the extraction repeated on the pellet with further $25 \mathrm{~mL}$ of $80 \%$ aqueous $\mathrm{CH}_{3} \mathrm{OH}$, supernatants were combined, filtered through a $0.2 \mu \mathrm{m}$ nylon filter and stored at $-18^{\circ} \mathrm{C}$ until analysis.

\subsection{Total Antioxidant Activity}

The free radical scavenging activity of the CHIs and CHPEs were evaluated using 2,2 ' azinobis-(3-ethylbenzthiazoline-6-sulphonic acid) (ABTS) radical cation decolorization (Re et al., 1999). The absorbance was calculated at $734 \mathrm{~nm}$, using a UV-VIS spectrophotometer. The 1,1-diphenyl-2-picrylhydrazyl (DPPH) free radical scavenging activity of samples was determined using the method by Yen \& Chen (1995). The antioxidant capacity based on the DPPH and ABTS free radical scavenging ability of the extract was expressed as mmol Trolox equivalents (TEAC) per $\mathrm{kg}$ of sample and all determinations were perfomed in triplicate.

\subsection{Determination of Total, Soluble, and Insoluble Fiber}

The amount total dietary fiber (TDF), insoluble dietary fiber (IDF) and soluble dietary fiber (SDF) was calculated according to a gravimetric enzymatic method AOAC Official Method 991.43 as the weight of residue minus the weight of protein and ash.

\subsection{UHPLC-High Resolution Mass Spectrometry (HRMS-Orbitrap) Analysis of Polyphenolic Compounds}

Qualitative and quantitative profile of polyphenols including caffeine has been obtained using Ultra High Pressure Liquid Chromatograph (UHPLC, Thermo Fisher Scientific, Waltham, MA, USA) equipped with a degassing system, a Dionex Ultimate 3000 a Quaternary UHPLC pump working at 1250 bar, an auto sampler device and a thermostated $\left(\mathrm{T}=25^{\circ} \mathrm{C}\right)$ Kinetex $1.7 \mu \mathrm{m}$ Biphenyl $(100 \times 2.1 \mathrm{~mm})$ column. Injection volume was of 2 $\mu \mathrm{L}$. Eluent phase was formed as follow: phase $\mathrm{A}\left(\mathrm{H}_{2} \mathrm{O}\right.$ in $0.1 \%$ formic acid), phase B (methanol in $0.1 \%$ formic acid). All metabolites were eluted using a $0.2 \mathrm{~mL} / \mathrm{min}$ flow rate with a gradient programmed as follows: 0 min $5 \%$ of phase B, $1.3 \mathrm{~min}-30 \%$ of phase B, $9.3 \mathrm{~min}-100 \%$ of phase B, $11.3 \mathrm{~min}-100 \%$ of phase B, $13.3 \mathrm{~min}-5 \%$ of phase B, $20 \mathrm{~min}-5 \%$ of phase $\mathrm{B}$.

For the mass spectrometry analysis a Q Exactive Orbitrap LC-MS/MS (Thermo Fisher Scientific, Waltham, MA, USA) has been used. An ESI source (HESI II, Thermo Fischer Scientific, Waltham, MA, USA) operating in negative ion mode (ESI-) for all the analyzed compounds and in positive (ESI+) ion mode for caffeine. Ion source parameters in (ESI-) mode were: spray voltage $-2.8 \mathrm{kV}$, sheath gas $\left(\mathrm{N}_{2}>95 \%\right) 45$, auxiliary gas $\left(\mathrm{N}_{2}>95 \%\right)$ 10 , capillary temperature $275^{\circ} \mathrm{C}$, S-lens RF level 50 , auxiliary gas heater temperature $305^{\circ} \mathrm{C}$. Value for automatic gain control (AGC) target was set at $1 \times 10^{6}$, with a resolution of 70,000 FWHM (full width at half maximum), and a scan rate in the range between 100 and $1000 \mathrm{~m} / \mathrm{z}$ in Full MS/Scan mode. Ion source parameters in (ESI+) mode used for alkaloides analysis were: spray voltage $3.3 \mathrm{kV}$, sheath gas $\left(\mathrm{N}_{2}>95 \%\right) 45$, auxiliary gas $\left(\mathrm{N}_{2}>95 \%\right)$ 13 , sweep gas 7 , capillary temperature $275^{\circ} \mathrm{C}$, S-lens RF level 50 , auxiliary gas heater temperature $305^{\circ} \mathrm{C}$. The 
AGC target value was of $1 \times 10^{6}$, the resolution set at 70,000 FWHM, with a scan rate in the range between 100 and $1000 \mathrm{~m} / \mathrm{z}$ in the Full MS mode.

The accuracy and calibration of the Q Exactive Orbitrap LC-MS/MS was checked daily using a reference standard mixture obtained from Thermo Fisher Scientific. The linearity of the method was assessed at both low (LOQ-5 mg/kg) and high $(5 \mathrm{mg} / \mathrm{kg}-120 \mathrm{mg} / \mathrm{kg}$ ) concentration ranges, using six concentration levels in each calibration range. Calibration curves for all compounds were prepared in triplicate. Sensitivity was evaluated by limits of detection (LODs) and limits of quantitation (LOQs). Data analysis and processing has been performer using the Xcalibur software, v. 3.0.63 (Xcalibur, Thermo Fisher Scientific).

The peaks for the studied compounds in the samples were confirmed by comparing the retention times of the peak with those of standards as well as by recognizing both the precursor and product ions with a mass error below 5 ppm.

\subsection{Microorganisms and Culture Conditions}

The strains of $P$. camemberti CECT 2267, P. expansum CECT 2278, P. roqueforti CECT 2905, A. parasiticus CECT 2681, A. niger CECT 2088, F. moniliformis CECT 2982, F. verticillioides CECT 20926, and $F$. graminearum CECT 20490 were provided by the Spanish Type Culture Collection (CECT, Valencia, Spain). The strain of A. flavus ITEM 8111 was obtained by the Agro Food Microbial Culture Collection of the Institute of Science of Food Production (Bari, Italy), and were preserved in sterile $30 \%$ glycerol at $-80{ }^{\circ} \mathrm{C}$. Therefore, they were mainteined in PDB broth at $25^{\circ} \mathrm{C}$ and inoculated in PDA plates.

\subsection{Antifungal Activity Tests on Solid Medium}

Agar well diffusion method used to evaluate the antimicrobial activity of the water and methanol extracts of coffee husks samples was performed according to (Madhyastha, Marquardt, Masi, Borsa \& Frohllch, 1994). Ten microliters of extract were added on sterile discs (6-mm Whatman No. 1, Madrid Spain). All strains were maintained in PDA for 7 days at $30^{\circ} \mathrm{C}$, and the spores were obtained at the time of analysis using $1 \mathrm{~mL}$ of distilled water added on the agar surface. After that, $100 \mu \mathrm{L}$ of a spore suspension was introduced in plate containing $10 \mathrm{~mL}$ of liquid PDA at $45^{\circ} \mathrm{C}$. Once the medium has solidified, the discs were placed on the agar surface. After refrigeration at $4{ }^{\circ} \mathrm{C}$ for $6 \mathrm{~h}$, the plates were incubated 7 days at $30^{\circ} \mathrm{C}$. After the fungal growth, the measurement of the inhibition halo diameter was carried out, being considered positive for antifungal activity halos larger than $8 \mathrm{~mm}$ around the disc.

\subsection{Determination of Minimum Inhibitory Concentration and MíNimum Fungicidal Concentration (MIC-MFC)}

The test was performed in liquid medium and 96 well clear polystyrene microplate, using the modified method of (Siah, Deweer, Morand, Reignault \& Halama, 2010). A volume of $100 \mu \mathrm{l}$ of water and methanol extracts of coffee husks at concentrations of $0.1,0.5,1,5,1050,100,250$ and $500 \mu \mathrm{g} / \mathrm{ml}$ was added in the wells. The wells were inoculated with the mycotoxigenic fungi using $100 \mu \mathrm{l}$ of a $10^{5}$ spores $/ \mathrm{ml}$ suspension in PDB. The negative control consisted of inoculated medium without any treatment. The microplates were incubated at $25^{\circ} \mathrm{C}$, on a rotary shaker at $140 \mathrm{rpm}$ for 7 days. The minimum inhibitory concentration (MIC) was defined as the lowest concentration of the coffee husk extract, that prevents visible fungal growth. Four replicates of each micro-assay were carried out and the experiment was repeated three times. For the Minimum Fungicidal Concentration (MFC) assay, the concentration corresponding to the MIC and higher were sub-cultured on PDA plates. The MFC is the lowest extract concentration in which a visible growth of the subculture was prevented after 3 days of incubation at $25^{\circ} \mathrm{C}$.

\subsection{Statistics and Data Analysis}

The experiments were done in triplicate. The results are given as mean standard deviation (SD). One-way analisys of variance (ANOVA) was applied to the data by the use of IBM SPSS (version 21). A difference was considered statistically significant when $\mathrm{p} \leq 0.05$.

\section{Results and Discussion}

\subsection{Determination of TDF, IDF and SDF}

Epidemiologic evidence suggests that a higher intake of dietary fiber and phytochemicals is associated with a lower risk of cardiovascular diseases and cancer (Petersen, Flock, Richter, Mukherjea, Slavin, \& Kris-Etherton, 2017). In this regard, the intake of dietary fiber in Western countries should increase to help prevent degenerative diseases (Fidanza \& Perriello, 2002). The amount of dietary fiber contained in CHIs and CHs are shown in Table 1. CHs as raw material for preparation of the new infusions showed amounts of TDF ranging from 367.45 to $396.04 \mathrm{~g} / \mathrm{kg}$ for dry and wet $\mathrm{CH}$ respectively, these results are according with the values reported in literature 
(from 245 to $430 \mathrm{~g} / \mathrm{kg}$ ) (Murthy \& Naidu, 2012b). The high content of SDF can be considered as a very positive aspect of CHs. The consumption of functional foods enriched with fiber-rich by-products from coffee, might increase the total dietary fiber intake, representing a nutritional strategy in reaching the recommended dietary allowance (RDA). CHI contain soluble food fibers (SDF) and phenolic compounds that represent compounds of nutritional value. The CHIs, in fact, contained exclusively soluble dietary fiber ranging from 0.64 to $0.98 \mathrm{~g}$ of SDF per liter (Table 1). The amount of SDF is comparable with that of Hibiscus sabdariffa L and may represent a significant nutritional and health promoting quality considering that SDF appear to profitably modify biomarkers of cardiovascular disease, including low-density lipoprotein cholesterol (LDL-C) and C-reactive protein (Ning, Van Horn, \& Lloyd-Jones, 2014).

Table 1. Comparison of DF content in CHIs and dry matter of $\mathrm{CH}$ and Roselle Flower (Hibiscus sabdariffa L.). The results are expressed in $\mathrm{g} / \mathrm{kg}$ dry weight and in $\mathrm{g} / \mathrm{L}$ of SDF in beverages

\begin{tabular}{lllll}
\hline & & CH1 & CH2 & Hibiscus sabdariffa L. \\
\hline TDF & Dry matter & $367.45 \pm 2.49^{\mathrm{a}}$ & $396.04 \pm 3.18^{\mathrm{b}}$ & $339.02 \pm 2.13^{\mathrm{c}}$ \\
& Infusion & $0.98 \pm 0.12^{\mathrm{a}}$ & $0.64 \pm 0.53^{\mathrm{b}}$ & $0.66 .14 \pm 0.33^{\mathrm{b}}$ \\
\hline IDF & Dry matter & $326.35 \pm 1.49^{\mathrm{a}}$ & $350.26 \pm 1.89^{\mathrm{b}}$ & $290.45 \pm 4.15^{\mathrm{c}}$ \\
& Infusion & ND & $\mathrm{ND}$ & ND \\
\hline SDF & Dry matter & $41.26 \pm 0.49^{\mathrm{a}}$ & $46.67 \pm 0.22^{\mathrm{b}}$ & $49.02 \pm 0.33^{\mathrm{c}}$ \\
& Infusion & $0.98 \pm 0.08^{\mathrm{a}}$ & $0.64 \pm 0.22^{\mathrm{b}}$ & $0.66 .45 \pm 0.13^{\mathrm{c}}$ \\
\hline
\end{tabular}

Value are \pm standard deviation of three independent determinations. The different superscripts in the same line with different letters are significantly different $(p<0.05)$

$\mathrm{SDF}=$ Soluble Dietary Fiber, IDF $=$ Insoluble Dietary Fiber, $\mathrm{TDF}=$ Total Dietary Fiber, $\mathrm{CH}=$ Coffee Husk and $\mathrm{ND}=$ Not detectable

\subsection{Total Antioxidant Activity}

The antioxidant activity was evaluated by ABTS and DPPH assays on row materials (CH1 and CH2), infusions (CHI) and polyphenol extracts (CHPE). The results are reported in Table 2. In particular, all samples showed antioxidant values ranged from 28.17 to 31.33 (ABTS assay) and from 26.61 to $29.55 \mathrm{TEAC} \mathrm{mmol} / \mathrm{kg}$ (DPPH assay). The results obtained with ABTS and DPPH assays showed a remarkable antioxidant activity of polyphenolic extract of two analyzed samples. The antioxidant activity linked to polyphenolic extract is found in the infusion, highlighting that most of the polyphenols with antioxidant activity are hydrophilic and therefore extracted during aqueous infusion. The procedure used for the CHIs preparation is able to exctract more than $90 \%$ of antioxidant capacity measured on CHPEs. Few reports are reported on coffee husk antioxidant activity. The authors reported that the higher free radical scavenging activity was exhibit by coffee husk extracts treated by low pressure methods, highlighting that ethanolic extraction using ultrasonic bath allows to obtain an extract with an antioxidant activity evaluated with ABTS radical of $161 \pm 3$ mmol TEAC/kg (Andrade et al., 2011). of $161 \pm 3 \mathrm{mmol}$ TEAC $/ \mathrm{kg}$ (Andrade et al., 2011). This value could be associated to the different coffee varieties and to different conditions of technological process. Our results about antioxidant activity measured with ABTS assay are comparable to those reported in literature, which shows that the coffee by-products have an appreciable free radical scavenging activity measured with ABTS assay: silverskin has the highest antioxidant activity (21.2 mmol Trolox $/ \mathrm{kg}$ ) followed by spent waste $(20.4 \mathrm{mmol}$ Trolox $/ \mathrm{kg})$, cherry husk $(18.4 \mathrm{mmol}$ Trolox $/ \mathrm{kg})$, and coffee pulp (15.3 mmol Trolox/kg) among the coffee byproducts (Murthy \& Naidu, 2012b). Data on DPPH antioxidant activity on coffee husk, in literature were expressed as AA\% and this prevents the comparison with our results. 
Table 2. Antioxidant activity in CHPE and CHI samples. The results are expressed in mmol TEAC/kg

\begin{tabular}{lllll}
\hline \multicolumn{3}{c}{ CH1 } & \multicolumn{3}{c}{ CH2 } \\
\hline Samples & ABTS & DPPH & ABTS & DPPH \\
\hline CHPE & $31.33 \pm 0.49^{\mathrm{a}}$ & $29.55 \pm 0.79^{\mathrm{a}}$ & $29.05 \pm 1.02^{\mathrm{a}}$ & $29.41 \pm 0.35^{\mathrm{a}}$ \\
CHI & $28.58 \pm 0.52^{\mathrm{b}}$ & $26.89 \pm 0.59^{\mathrm{b}}$ & $28.17 \pm 0.59^{\mathrm{a}}$ & $26.61 \pm 0.59^{\mathrm{b}}$ \\
\hline
\end{tabular}

Value are \pm standard deviation of three independent determinations. The different superscripts in the same column with different letters are significantly different $(p<0.05)$

$\mathrm{CH}$ - Coffee Husk sample

CHPE - Coffee Husk polyphenol extract

CHI - Coffee Husk infusion

\subsection{Identification of the Bioactive Compounds in Coffee Husks and in Infusion by High-resolution Mass} Spectrometry (HRMS-Orbitrap)

A Q Exactive Orbitrap LC-MS/MS has been used for the mass spectrometry analysis. An ESI source operating in Full MS/Scan and PRM mode, both in negative (ESI-) and in positive (ESI+) ion mode was used for all the analyzed compounds. Qualitative data regarding the phenolic compounds of coffee husk extracts are shown in Table 3. In this work, the bioactive compounds has been identified by using MS/MS experiments; accurate mass measurements and precursor ion scan. The isotopic patter and accurate masses were selected for to establish the element composition. The strategies for identification of polyphenols were based on observed MS/MS spectra than those in the literature. Table 3 reported the 30 compounds identified using triple-quadrupole MS/MS and Orbitrap experiments, in addition to theoretical and measured mass, accuracy, molecular formula, retention times, collision energy and the fragment ions exploited for the identification. 
Table 3. Peak Numbers, Compound name, formula, Ionization mode, Theoretical and Measured $(\mathrm{m} / \mathrm{z})$, Accuracy, fragment ion, collision energy and retention time

\begin{tabular}{|c|c|c|c|c|c|c|c|c|c|}
\hline Peak & Compound & Formula & $\begin{array}{l}\text { Ionization } \\
\text { mode }\end{array}$ & $\begin{array}{l}\text { Theoretical } \\
(m / z)\end{array}$ & $\begin{array}{l}\text { Measured } \\
(\mathrm{m} / z)\end{array}$ & $\begin{array}{l}\text { Accuracy } \\
(\Delta \mathrm{mg} / \mathrm{kg})\end{array}$ & $\begin{array}{l}\text { Fragment } \\
\text { ions }(m / z)\end{array}$ & $\begin{array}{l}\text { CE } \\
(\mathrm{V})\end{array}$ & $\begin{array}{l}\text { RT } \\
(\min )\end{array}$ \\
\hline 1 & Trigonelline & $\mathrm{C}_{7} \mathrm{H}_{7} \mathrm{NO}_{2}$ & {$[\mathrm{M}-\mathrm{H}]^{+}$} & 13.805 .496 & 13.805 .514 & 1.30 & 11.006 .006 & 30 & 1.44 \\
\hline 2 & Gallic Acid & $\mathrm{C}_{7} \mathrm{H}_{6} \mathrm{O}_{5}$ & {$[\mathrm{M}-\mathrm{H}]^{-}$} & 16.901 .425 & 1.690 .147 & 2.66 & $125.02428 ; 169.01406$ & 20 & 2.37 \\
\hline 3 & Protocatecuic Acid & $\mathrm{C}_{7} \mathrm{H}_{6} \mathrm{O}_{4}$ & {$[\mathrm{M}-\mathrm{H}]^{-}$} & 15.301 .933 & 15.301 .953 & 1.31 & 10.902 .933 & 20 & 5 \\
\hline 4 & 3-O-caffeoylquinic acid & $\mathrm{C}_{16} \mathrm{H}_{18} \mathrm{O}_{9}$ & {$[\mathrm{M}-\mathrm{H}]^{-}$} & 35.308 .781 & 35.308 .817 & 1.02 & $191.05609 ; 179.03481 ; 135.04508$ & 20 & 7.06 \\
\hline 5 & (+)-catechin & $\mathrm{C}_{15} \mathrm{H}_{14} \mathrm{O}_{6}$ & {$[\mathrm{M}-\mathrm{H}]^{-}$} & 28.907 .176 & 28.907 .186 & 0.35 & $245.08187 ; 203.07126 ; 205.05025$ & 20 & 7.79 \\
\hline 6 & 5-p-Coumaroylquinic Acid & $\mathrm{C}_{16} \mathrm{H}_{18} \mathrm{O}_{8}$ & {$[\mathrm{M}-\mathrm{H}]^{-}$} & 33.709 .289 & 33.709 .338 & 1.45 & $191.05598 ; \quad 173.04520 ; 163.03989$ & 20 & 7.94 \\
\hline 7 & 5-O-caffeoylquinic acid & $\mathrm{C}_{16} \mathrm{H}_{18} \mathrm{O}_{9}$ & {$[\mathrm{M}-\mathrm{H}]^{-}$} & 35.308 .781 & 35.308 .796 & 0.42 & $191.05609 ; 179.03478$ & 20 & 8.25 \\
\hline 8 & Caffeic acid & $\mathrm{C}_{9} \mathrm{H}_{8} \mathrm{O}_{4}$ & {$[\mathrm{M}-\mathrm{H}]^{-}$} & 17.903 .498 & 17.903 .507 & 0.50 & 13.504 .503 & 20 & 8.37 \\
\hline 9 & Theobromine & $\mathrm{C}_{7} \mathrm{H}_{8} \mathrm{~N}_{4} \mathrm{O}_{2}$ & {$[\mathrm{M}-\mathrm{H}]^{+}$} & 18.107.200 & 18.107.208 & 0.44 & 110.07130; 163.06142; 135.06652; & 30 & 8.55 \\
\hline 10 & procyanidin A type trimer & $\mathrm{C}_{45} \mathrm{H}_{36} \mathrm{O}_{18}$ & {$[\mathrm{M}-\mathrm{H}]^{-}$} & 86.318 .290 & 86.318 .502 & 2.46 & 57.512 .382 & 25 & 8.57 \\
\hline 11 & Gentisic Acid & $\mathrm{C}_{7} \mathrm{H}_{6} \mathrm{O}_{4}$ & {$[\mathrm{M}-\mathrm{H}]^{-}$} & 15.301 .933 & 15.301 .949 & 1.05 & 10.902 .936 & 20 & 8.66 \\
\hline 12 & Theofillyne & $\mathrm{C}_{7} \mathrm{H}_{8} \mathrm{~N}_{4} \mathrm{O}_{2}$ & {$[\mathrm{M}-\mathrm{H}]^{+}$} & 18.107.200 & 18.107.209 & 0.50 & $69.04483 ; 124.05061 ; 96.05561$ & 30 & 8.67 \\
\hline 13 & $(-)$-epicatechin & $\mathrm{C}_{15} \mathrm{H}_{14} \mathrm{O}_{6}$ & {$[\mathrm{M}-\mathrm{H}]^{-}$} & 28.907 .176 & 28.907 .218 & 1.45 & $245.08163 ; 205.05034$ & 20 & 8.7 \\
\hline 14 & 4- $O$-caffeoylquinic acid & $\mathrm{C}_{16} \mathrm{H}_{18} \mathrm{O}_{9}$ & {$[\mathrm{M}-\mathrm{H}]^{-}$} & 35.308 .781 & 35.308 .826 & 1.27 & $173.04537 ; 191.05589 ; 179.03484$ & 20 & 8.93 \\
\hline 15 & procyanidin $B$ type trimer & $\mathrm{C}_{45} \mathrm{H}_{38} \mathrm{O}_{18}$ & {$[\mathrm{M}-\mathrm{H}]^{-}$} & 86.519 .854 & 86.520 .035 & 2.09 & $577.13519 ; 287.05609 ; 289.07185$ & 40 & 8.93 \\
\hline 16 & 4-O-feruloylquinic acid & $\mathrm{C}_{17} \mathrm{H}_{20} \mathrm{O}_{9}$ & {$[\mathrm{M}-\mathrm{H}]^{-}$} & 36.710 .346 & 36.710 .370 & 0.65 & 19.105.609 & 20 & 9.33 \\
\hline 17 & $p$-Coumaric Acid & $\mathrm{C}_{9} \mathrm{H}_{8} \mathrm{O}_{3}$ & {$[\mathrm{M}-\mathrm{H}]^{-}$} & 16.304 .007 & 16.304 .037 & 1.84 & 11.905 .014 & 20 & 9.56 \\
\hline 18 & 5-O-feruloylquinic acid & $\mathrm{C}_{17} \mathrm{H}_{20} \mathrm{O}_{9}$ & {$[\mathrm{M}-\mathrm{H}]^{-}$} & 36.710 .346 & 36.710 .357 & 0.30 & $191.05600 ; 173.04537$ & 30 & 9.6 \\
\hline 19 & 3,4-O-dicaffeoylquinic acid & $\mathrm{C}_{25} \mathrm{H}_{24} \mathrm{O}_{12}$ & {$[\mathrm{M}-\mathrm{H}]^{-}$} & 51.511 .950 & 51.511 .982 & 0.62 & $\begin{array}{l}353.08744 ; 173.04527 \\
179.03477 ; 335.07697\end{array}$ & 25 & 9.93 \\
\hline 20 & quercetin-3- $O$-rutinoside & $\mathrm{C}_{27} \mathrm{H}_{30} \mathrm{O}_{16}$ & {$[\mathrm{M}-\mathrm{H}]^{-}$} & 60.914 .611 & 60.914 .685 & 1.21 & 30.103 .514 & 30 & 10 \\
\hline 21 & 3,5-O-dicaffeoylquinic acid & $\mathrm{C}_{25} \mathrm{H}_{24} \mathrm{O}_{12}$ & {$[\mathrm{M}-\mathrm{H}]^{-}$} & 51.511 .950 & 51.511 .986 & 0.70 & 17.903 .486 & 30 & 10.06 \\
\hline 22 & quercetin-3-O-glucoside & $\mathrm{C}_{21} \mathrm{H}_{20} \mathrm{O}_{12}$ & {$[\mathrm{M}-\mathrm{H}]^{-}$} & 46.308 .820 & 46.308 .888 & 1.47 & 30.103 .465 & 32 & 10.16 \\
\hline 23 & Ferulic acid & $\mathrm{C}_{10} \mathrm{H}_{10} \mathrm{O}_{4}$ & {$[\mathrm{M}-\mathrm{H}]^{-}$} & 19.305.063 & 19.305.070 & 0.36 & $149.00352 ; 134.03721 ; 178.02727$ & 20 & 10.16 \\
\hline 24 & 4,5-O-dicaffeoylquinic acid & $\mathrm{C}_{25} \mathrm{H}_{24} \mathrm{O}_{12}$ & {$[\mathrm{M}-\mathrm{H}]^{-}$} & 51.511 .950 & 51.511 .983 & 0.64 & 35.308 .725 & & 10.49 \\
\hline 25 & Luteolin-7-O-glucoside & $\mathrm{C}_{21} \mathrm{H}_{20} \mathrm{O}_{11}$ & {$[\mathrm{M}-\mathrm{H}]^{-}$} & 44.709 .328 & 44.709 .363 & 0.78 & 28.504 .044 & 30 & 10.6 \\
\hline 26 & Isorhamnetin 3-O-Rutinoside & $\mathrm{C}_{28} \mathrm{H}_{32} \mathrm{O}_{16}$ & {$[\mathrm{M}-\mathrm{H}]^{-}$} & 62.316 .176 & 62.316 .241 & 1.04 & 31.505 .104 & 30 & 10.64 \\
\hline 27 & Caffeine & $\mathrm{C}_{8} \mathrm{H}_{10} \mathrm{~N}_{4} \mathrm{O}_{2}$ & {$[\mathrm{M}-\mathrm{H}]^{+}$} & 19.508 .765 & 19.508 .780 & 0.77 & $138.06617 ; 110.0713$ & 25 & 10.74 \\
\hline 28 & 3- $O$-Feruloyl-4- $O$-caffeoylquinic acid & $\mathrm{C}_{26} \mathrm{H}_{26} \mathrm{O}_{12}$ & {$[\mathrm{M}-\mathrm{H}]^{-}$} & 52.913 .515 & 52.913 .538 & 0.43 & $367.10296 ; 335.07703$ & 25 & 10.85 \\
\hline 29 & 4- $O$-Caffeoyl-5- $O$-feruloylquinic acid & $\mathrm{C}_{26} \mathrm{H}_{26} \mathrm{O}_{12}$ & {$[\mathrm{M}-\mathrm{H}]^{-}$} & 52.913 .515 & 52.913 .594 & 1.49 & $367.10318 ; 335.07699$ & 25 & 11.41 \\
\hline 30 & Naringenin & $\mathrm{C}_{15} \mathrm{H}_{12} \mathrm{O}_{5}$ & {$[\mathrm{M}-\mathrm{H}]^{-}$} & 27.106 .120 & 27.106 .156 & 1.33 & $151.00355 ; 119.05012 ; 271.06118$ & 20 & 12.08 \\
\hline
\end{tabular}

The discrimination among isomers of CGA was done using their fragmentation pattern in $\mathrm{MS}^{2}$ and their relative intensity, in accordance with the hierarchical scheme of identification described by (Clifford, Johnston, Knight, $\&$ Kuhnert, 2003). For the peaks 4, 7 and 14 mass spectral analysis showed the same molecular ion negatively charged $[\mathrm{M}-\mathrm{H}]^{-}$at $\mathrm{m} / \mathrm{z}$ 353.08781. The isomers produced different mass spectra in-source fragmentation of $\mathrm{m} / \mathrm{z}$ 353. 08781 which allowed distinguish the different compounds.

These 3 isomers were differentiated by the $\mathrm{MS}^{2}$ fragmentation pattern. The 4-CQA (peak 14) showed a $\mathrm{MS}^{2}$ base peak at $\mathrm{m} / \mathrm{z} 173.04537$ ([quinic acid- $\mathrm{H}-\mathrm{H}_{2} \mathrm{O}$ ]) due to the dehydration of the quinic acid ion, a feature of cinnamoyl group bonded to the quinic acid moiety at the position 4. The 3-CQA (peak 4) and 5-CQA (peak 7) showed the same $\mathrm{MS}^{2}$ base peak at $\mathrm{m} / \mathrm{z} 191.05609$ ([quinic acid-H]) and they could be distinguished by comparing the relative intensity of the secondary ion from caffeoyl moiety ([caffeic acid-H]) at $m / z, 179.03498$ (Rodrigues \& Bragagnolo, 2013). Peak 6 showed MS² base peak at $\mathrm{m} / z 191.05609$ ([quinic acid-H]).

Peaks 16 and 18 with $[\mathrm{M}-\mathrm{H}]^{-}$ions at $\mathrm{m} / \mathrm{z} 367.10346$ indicating the presence of feruloylquinic acids. 4- $O$-feruloylquinic acid showed a single fragment $\mathrm{MS}^{2}$ base peak at $\mathrm{m} / z$ 191.05605. Peak 18 generated fragment ion at $\mathrm{m} / \mathrm{z} 191.05605$ with additional minor ion at $\mathrm{m} / \mathrm{z} 173.04537$ in keeping with that previously described for Peak 16.

Peaks 19, 21, and 24 with $[\mathrm{M}-\mathrm{H}]^{-}$ions at $\mathrm{m} / \mathrm{z} 515.1195$ were identified as di-CQA isomers according to the formula $\mathrm{C}_{25} \mathrm{H}_{23} \mathrm{O}_{12}{ }^{-}$. Dicaffeoylquinic acid isomers showed peaks at $\mathrm{m} / z .353$ and 515 , which confirmed the losses of two caffeic acid units. The analysis in the LTQ-Orbitrap confirmed their presence showing the deprotonated molecule $[\mathrm{M}-\mathrm{H}]^{-}(\mathrm{m} / \mathrm{z}, 515)$, the ion $[\mathrm{M}-\mathrm{H}-162]^{-}(\mathrm{m} / \mathrm{z}, 353)$, corresponding to the loss of a caffeic acid unit and the deprotonated caffeic acid $(\mathrm{m} / \mathrm{z}, 179)$. Peaks 28 and 29 showing a fragmentation pattern characterized by predominant ion $[\mathrm{M}-\mathrm{H}]^{-}$at $\mathrm{m} / z$ 529.13515 this daughter ion is indicative of an $O$-caffeoyl- $O$-feruloyl quinic acid conjugated compound. Peaks 28 and 29 showed a MS ${ }^{2}$ base peak at $\mathrm{m} / z$ 367.10296 and the fragmentation spectra showed an additional fragment ions at $\mathrm{m} / \mathrm{z}$ 335.07703. This would suggest that these compounds are the 3-O-feruloyl-4- $O$-caffeoylquinic acid isomers. 
The ionization in the positive mode generated the protonated molecule $[\mathrm{M}+\mathrm{H}]^{+}$for alkaloids. Theobromine and theophylline are methyl xanthines, which are intermediates of caffeine metabolism. Peak 9 and 12 were differentiated by $\mathrm{MS}^{2}$ fragmentation pattern. The fragmentation pathway was characterized by base peak at $\mathrm{m} / \mathrm{z}$ 110.07130 and 69.04483, this suggest the loss of $\mathrm{C}_{3} \mathrm{H}_{3} \mathrm{NO}_{2}$ (cyanoformate) and $\mathrm{C}_{4} \mathrm{H}_{4} \mathrm{~N}_{2} \mathrm{O}_{2}$ (diisocyanatoethane), respectively. Trigonelline (Peak 1) $\mathrm{m} / z, 138.05496$ shows a fragmentation pattern with the parent ion producing a single fragment at $\mathrm{m} / \mathrm{z}$ 110.06006. Caffeine (Peak 27) in $\mathrm{MS}^{2}$ fragmentation shows the base daughter ion at $\mathrm{m} / \mathrm{z}$ 138.06617 corresponded to loss of $\mathrm{C}_{2} \mathrm{H}_{3} \mathrm{NO}$ methylcarbamoyl.

For cinnamic and benzoic acids the spectra showed the deprotonated molecule $[\mathrm{M}-\mathrm{H}]$. For ferulic, caffeic, protocatechuic, gentisic, $p$-coumaric and gallic acid loss of $\mathrm{CO}_{2}$ was observed, giving as a characteristic ion the [M-H-44] $]^{-}$(Rabaneda et al., 2003). Peak 5 and 13 showed the same $\mathrm{MS}^{2}$ base peak at $\mathrm{m} / \mathrm{z} 245.08187$ this suggest the loss of $\mathrm{CH}_{2} \mathrm{CHOH}$ group (Pèrez, Revilla, Gonzàlez-SanJosè, \& Beltràn, 1999).

For flavonol $O$-glycosides such as quercetin-3- $O$-rutinoside, quercetin-3- $O$-glucoside, luteolin-7- $O$-glucoside and isorhamnetin 3-O-rutinoside the spectra generated with a collision energy (CE) between -30 and $-32 \mathrm{~V}$ revealed both the deprotonated molecule $[\mathrm{M}-\mathrm{H}]^{-}$of the glycoside and the ion corresponding to the deprotonated aglycone $[\mathrm{A}-\mathrm{H}]^{-}$. For Peak 30 the fragmentation pathway was characterized by base peak at $\mathrm{m} / \mathrm{z} .151 .00355$ and 119.05012 characteristic for naringenin and its derivatives (Rabaneda et al., 2003). For peaks 10 and 15 loss of catechin residue was observed, obtaining the base daughter ion [M-H-288] ${ }^{-}$at $\mathrm{m} / \mathrm{z} 575.12382$ and 577.13519, respectively.

\subsection{Quantification of Major and Minor Compounds Found in Coffee Husks and in Infusion}

The CGAs identified and quantified in CHPEs and CHIs showed in Table 4 and the results are expressed as $\mathrm{mg} / \mathrm{kg}$. In CHPEs the results showed amounts of CGA ranging from 1019.19 to 1564.68 for CHPE1 and CHPE2, respectively. The infusion contains an amount of CGA ranging from 370.22 to 608.11 for CHI1 and CHI2, respectively. In all samples the 5-O-caffeoylquinic acid was the major CGA present, in according with the work of (Mullen, Nemzer, Stalmach, Ali, \& Comb, 2013). Even the 5-O-feruloylquinic acid was present in high quantities, no statistically significant differences among samples of the same type were observed. Dicaffeoylquinic acid isomers, 3-O-Feruloyl-4- $O$-caffeoylquinic acid and 4- $O$-Caffeoyl-5- $O$-feruloylquinic were not detected in CHIs.

Table 4. Quantification of Major Compounds in CHPEs and CHIs in $\mathrm{mg} / \mathrm{kg}$, LOD and LOQ value in $\mu \mathrm{g} / \mathrm{kg}$

\begin{tabular}{lllllll}
\hline Compound & CHPE 1 & CHPE 2 & CHI 1 & CHI 2 & LOD & LOQ \\
\hline 3- $O$-caffeoylquinic acid & $24.41 \pm 0.09$ & $53.34 \pm 0.88$ & $8.34 \pm 0.19$ & $19.01 \pm 0.93$ & 0.07 & 0.20 \\
5- -Coumaroylquinic Acid & $35.12 \pm 0.19$ & $61.55 \pm 0.76$ & $8.82 \pm 0.12$ & $20.23 \pm 0.43$ & 0.07 & 0.20 \\
5- $O$-caffeoylquinic acid & $654.72 \pm 2.49$ & $1121.7 \pm 5.22$ & $283.32 \pm 0.12$ & $502.0 \pm 3.59$ & 0.07 & 0.20 \\
4- $O$-caffeoylquinic acid & $7.62 \pm 0.04$ & $11.12 \pm 0.49$ & $<\mathrm{LOQ}$ & $<\mathrm{LOQ}$ & 0.07 & 0.20 \\
4- $O$-feruloylquinic acid & $15.21 \pm 0.11$ & $14.72 \pm 0.77$ & $5.32 \pm 0.12$ & $5.34 \pm 0.12$ & 0.07 & 0.20 \\
5- $O$-feruloylquinic acid & $170.32 \pm 3.29$ & $171.82 \pm 1.43$ & $64.42 \pm 0.43$ & $61.53 \pm 0.34$ & 0.07 & 0.20 \\
3,4- $O$-dicaffeoylquinic acid & $22.82 \pm 0.53$ & $20.21 \pm 0.14$ & $<\mathrm{LOQ}$ & $<\mathrm{LOQ}$ & 0.07 & 0.20 \\
3,5- $O$-dicaffeoylquinic acid & $62.42 \pm 0.23$ & $65.51 \pm 1.12$ & $<\mathrm{LOQ}$ & $<\mathrm{LOQ}$ & 0.07 & 0.20 \\
4,5- $O$-dicaffeoylquinic acid & $18.28 \pm 0.12$ & $34.41 \pm 1.23$ & $<\mathrm{LOQ}$ & $<\mathrm{LOQ}$ & 0.07 & 0.20 \\
3- $O$-Feruloyl-4-O-caffeoylquinic acid & $8.62 \pm 0.13$ & $8.84 \pm 0.22$ & $<\mathrm{LOQ}$ & $<\mathrm{LOQ}$ & 0.07 & 0.20 \\
4- $O$-Caffeoyl-5-O-feruloylquinic acid & $0.4 \pm 0.09$ & $1.46 \pm 0.02$ & $<\mathrm{LOQ}$ & $<\mathrm{LOQ}$ & 0.07 & 0.20 \\
\hline Total major compounds & 1019.19 & 1564.68 & 370.22 & 608.11 & & \\
\hline
\end{tabular}

Value are \pm standard deviation of three independent determinations.

CHPE - Coffee Husk polyphenol extract

CHI - Coffee Husk infusion

LOD - Limit of Detection

LOQ - Limit of Quantification

The quantitative data on the alkaloids compounds found in the CHPEs and CHIs are reported in Table 5. The results showed that caffeine and trigonelline were the most predominant alkaloids according to literature data (Mullen et al., 2003). 
Table 5. Quantification of alkaloids in CHPEs and CHIs in $\mathrm{mg} / \mathrm{kg}$, LOD and LOQ value in $\mu \mathrm{g} / \mathrm{kg}$

\begin{tabular}{lllllll}
\hline Compound & CHPE 1 & CHPE 2 & CHI 1 & CHI 2 & LOD & LOQ \\
\hline Trigonelline & $1825.72 \pm 3.39^{\mathrm{a}}$ & $1559.00 \pm 5.49^{\mathrm{b}}$ & $558.02 \pm 1.55^{\mathrm{c}}$ & $550.45 \pm 1.39^{\mathrm{d}}$ & 0.011 & 0.02 \\
Theobromine & $5.33 \pm 0.21^{\mathrm{a}}$ & $4.42 \pm 0.19^{\mathrm{b}}$ & $2.15 \pm 0.03^{\mathrm{c}}$ & $1.19 \pm 0.03^{\mathrm{d}}$ & 0.008 & 0.03 \\
Theofillyne & $15.04 \pm 0.09^{\mathrm{a}}$ & $8.6 \pm 0.24^{\mathrm{b}}$ & $4.82 \pm 0.22^{\mathrm{c}}$ & $3.05 \pm 0.11^{\mathrm{d}}$ & 0.008 & 0.03 \\
Caffeine & $1327.39 \pm 5.41^{\mathrm{a}}$ & $1334.5 \pm 4.23^{\mathrm{a}}$ & $506.32 \pm 0.29^{\mathrm{b}}$ & $553.25 \pm 1.28^{\mathrm{c}}$ & 0.009 & 0.02 \\
\hline Total alkaloids & 3173.48 & 2906.52 & 1066.49 & 1107.94 & & \\
\hline
\end{tabular}

Value are \pm standard deviation of three independent determinations. The different superscripts in the same line with different letters are significantly different $(p<0.05)$

CHI - Coffee Husk sample

CHPE - Coffee Husk polyphenol extract sample

LOD - Limit of Detection

LOQ - Limit of Quantification

The total amount of caffeine and trigonelline extracted with the infusion is approximately 2-3 times lower than CHPEs. The caffeine content in coffee husk in literature ranged from 1300 to $8200 \mathrm{mg} / \mathrm{kg}$, values significantly higher than all the analyzed samples (Mennini et al., 2013; Heeger et al., 2016; Mullen et al., 2003). Theophylline and theobromine (methyl xanthines, intermediates of the caffeine metabolism) were few represented both in CHPEs and CHIs, however there are no terms of comparison in literature.

Table 6 shown the quantitative data on the minor flavonoid compounds present in the samples. In particular, phenolic acids, flavan-3-ols and flavonoids were detected and quantified in the CHPEs whereas in CHIs, were found only six phenolic compounds (protocatecuic acid, caffeic acid, epicatechin, rutin, Isorhamnetin 3-O-rutinoside and naringenin).

Table 6. Quantification of minor compounds in CHPEs and CHIs in $\mathrm{mg} / \mathrm{kg}$, LOD and LOQ value in $\mu \mathrm{g} / \mathrm{kg}$.

\begin{tabular}{|c|c|c|c|c|c|c|}
\hline Compound & CHPE 1 & CHPE 2 & CHI 1 & CHI 2 & LOD & LOQ \\
\hline Gallic Acid & $3.22 \pm 0.09^{\mathrm{a}}$ & $1.90 \pm 0.01^{\mathrm{b}}$ & $<\mathrm{LOQ}$ & $<\mathrm{LOQ}$ & 0.07 & 0.20 \\
\hline Protocatecuic Acid & $48.94 \pm 0.22^{\mathrm{a}}$ & $37.42 \pm 0.78^{b}$ & $10.62 \pm 039^{c}$ & $5.05 \pm 0.32^{\mathrm{d}}$ & 0.07 & 0.20 \\
\hline (+)-catechin & $1.55 \pm 0.09^{\mathrm{a}}$ & $0.82 \pm 0.01^{\mathrm{b}}$ & $<\mathrm{LOQ}$ & $<\mathrm{LOQ}$ & 0.06 & 0.18 \\
\hline Caffeic acid & $6.12 \pm 0.05^{\mathrm{a}}$ & $18.33 \pm 0.07^{\mathrm{b}}$ & $0.75 \pm 0.01^{\mathrm{c}}$ & $2.14 \pm 0.09^{\mathrm{d}}$ & 0.06 & 0.18 \\
\hline n A type trimer & $4.74 \pm 0.12^{\mathrm{a}}$ & $0.62 \pm 0.02^{\mathrm{b}}$ & $<\mathrm{LOQ}$ & $<\mathrm{LOQ}$ & 0.06 & 0.18 \\
\hline Gentisic Acid & $77.13 \pm 1.12^{\mathrm{a}}$ & $27.37 \pm 0.33^{\mathrm{b}}$ & $<\mathrm{LOQ}$ & $<\mathrm{LOQ}$ & 0.06 & 0.18 \\
\hline$(-)$-epicatechin & $24.95 \pm 0.33^{\mathrm{a}}$ & $7.97 \pm 0.24^{b}$ & $0.19 \pm 0.03^{\mathrm{c}}$ & $0.13 \pm 0.09^{\mathrm{d}}$ & 0.06 & 0.18 \\
\hline procyanidin B type trimer & $12.52 \pm 0.12^{\mathrm{a}}$ & $3.27 \pm 0.07^{\mathrm{b}}$ & $<\mathrm{LOQ}$ & $<\mathrm{LOQ}$ & 0.06 & 0.18 \\
\hline$p$-Coumaric Acid & $0.41 \pm 0.01^{\mathrm{a}}$ & $4.56 \pm 0.09^{b}$ & $<\mathrm{LOQ}$ & $<$ LOQ & 0.07 & 0.20 \\
\hline quercetin-3-O-rutinoside & $95.82 \pm 1.12^{\mathrm{a}}$ & $114.95 \pm 5.12^{\mathrm{b}}$ & $10.95 \pm 0.09^{c}$ & $9.85 \pm 0.09^{\mathrm{d}}$ & 0.07 & 0.20 \\
\hline quercetin-3-O-glucoside & $69.87 \pm 0.93^{\mathrm{a}}$ & $67.06 \pm 0.89^{\mathrm{b}}$ & $<\mathrm{LOQ}$ & $<\mathrm{LOQ}$ & 0.07 & 0.20 \\
\hline Ferulic acid & $10.24 \pm 0.22$ & ND & $<\mathrm{LOQ}$ & $<\mathrm{LOQ}$ & 0.07 & 0.20 \\
\hline Luteolin-7-O-glucoside & $10.27 \pm 0.39^{\mathrm{a}}$ & $5.74 \pm 0.09^{\mathrm{b}}$ & $<\mathrm{LOQ}$ & $<\mathrm{LOQ}$ & 0.06 & 0.18 \\
\hline Isorhamnetin 3-O-Rutinoside & $6.67 \pm 0.31^{\mathrm{a}}$ & $5.23 \pm 0.02^{\mathrm{b}}$ & $0.65 \pm 0.02^{c}$ & $0.57 \pm 0.29^{\mathrm{d}}$ & 0.07 & 0.20 \\
\hline Naringenin & $1.32 \pm 0.19^{\mathrm{a}}$ & $1.94 \pm 0.01^{\mathrm{b}}$ & $0.14 \pm 0.01^{\mathrm{c}}$ & $0.18 \pm 0.09^{\mathrm{d}}$ & 0.06 & 0.18 \\
\hline Total minor compounds & 373.67 & 297.18 & 23.30 & 17.92 & & \\
\hline
\end{tabular}

Value are \pm standard deviation of three independent determinations. The different superscripts in the same line with different letters are significantly different $(p<0.05)$

$\mathrm{CH}$ - Coffee Husk sample

CHPE - Coffee Husk polyphenol extract sample

LOD - Limit of Detection

LOQ - Limit of Quantification

\subsection{Water and Methanol Coffee Husk Extracts Antifungal Activity, MIC-MFC}

Coffee is the most preferred morning beverage throughout the world due to its pleasant flavor and stimulating properties. Natural preservatives have been developed as an alternative source of novel antimicrobials in encountering food-borne pathogens. In recent years, coffee has been associated with antimicrobial activity against a number of different bacteria and fungi (Daglia, Cuzzoni, \& Dacarro, 1994). 
The active components or the antimicrobial mechanism of coffee are not fully elucidated yet. In the current study, the eight major primary or secondary components of roasted coffee for which an antibacterial activity has been reported before, were not investigated. Coffee is composed by several compounds such as water, caffeine, lipids, tannic acids, mineral substances, glucides, theobromine, organic acids, alkaloids, and several vitamins, that could be responsible of its antimicrobial effects. Possible candidates include complex mixtures of phenolic compounds or, in the case of roasted coffee, Maillard reaction polymers such as melanoidins (Daglia et al., 1994; Rufián-Henares \& De la Cueva, 2009).

The antimicrobial mechanism of action of the phenolic compounds is not clear. They can express their antimicrobial activity by changing the cytoplasmic membrane's structure, disrupting the active transport, the proton motive force and/or the electron flow. Additionally, the mechanism for phenolic toxicity may include enzymatic inhibition by the oxidized compounds, probably through interaction with sulfidryl groups or through more non-specific reactions with proteins (Lou, Wang, Zhu, Ma, \& Wang, 2011).

In Table 7 are evidenced the data related to the antifungal activity on solid medium of the water and methanol extracts of the two coffee husks samples. In particular the water extracts of the two samples tested do not presented any antifungal activity against the mycotoxigenic fungi assayed, whereas both methanol extracts presented an antifungal activity quantified with a diameter clearing zone of $8 \mathrm{~mm}$ on the three strains of Penicillium, and also on A. flavus and A. niger. The antifungal activity evidenced by the methanol extracts of the two coffee husks samples was quantified through the Minimum inhibitory Concentration and the Minimum Fungicidal Concentration (MIC-MFC) evaluation calculated using the 96-well microplates assay. In particular as evidenced in the Table 8 the methanol extract of the sample 1 presented a MIC variable from 6.3 to $25 \mathrm{~g} / \mathrm{L}$, considering that the most sensible strains to this natural antimicrobial complex were P. expansum and P. roqueforti with 6.3 and $12.5 \mathrm{~g} / \mathrm{L}$. The MFC data observed for the antimicrobial complex produced through the methanol extract of the sample 1, ranged from 6.3 to $50 \mathrm{~g} / \mathrm{L}$, confirming that the strains most sensible to this treatment was the P. expansum. The MIC data evidenced for the methanol extracts of the sample 2, ranged from 6.0 to $50 \mathrm{~g} / \mathrm{L}$. The highest sensibility of this extract was observed on the strain of P. expansum, whereas the lowest sensibility was observed on the strain of A. flavus and A. niger. The data evidenced for the MFC of the sample two-methanol extract ranged from 12.5 to $50 \mathrm{~g} / \mathrm{L}$. Finally considering in general the two samples extracts tested, an important antifungal activity was observed on the P. expansum strains, concluding that this extract could be considered a good candidate for the biocontrol of this mycotoxigenic fungi in food and feed chain.

Table 7. Antifungal activity in solid medium evidenced by Coffee husk 1 and Coffee husk 2 water and methanolic extracts on the mycotoxigenic fungi tested. Calculation of antifungal activity: $8 \mathrm{~mm}$ diameter clearing zone (+), $10 \mathrm{~mm}$ diameter clearing zone $(++)$, and more than $10 \mathrm{~mm}$ diameter clearing zone $(+++)$.

\begin{tabular}{lccccc}
\hline \multicolumn{1}{c}{ Fungi } & \multicolumn{2}{c}{ CH1 } & \multicolumn{3}{c}{ CH2 } \\
\hline P. camemberti CECT 2267 & Water extract & Methanol extract & Water extract & Methanol extract \\
P. expansum CECT 2278 & - & - & + & - & + \\
P. roqueforti CECT 2905 & - & + & - & + \\
A. parasiticus CECT 2681 & - & + & - & + \\
A. flavus ITEM 8111 & - & - & - & - \\
A. niger CECT 2088 & - & + & - & + \\
F. moniliformis CECT 2982 & - & - & - & + \\
F. verticilliodes CECT 20926 & - & - & - & - \\
F. graminearum CECT 20490 & - & - & - & - \\
\hline
\end{tabular}

$\mathrm{CH}$ - Coffee Husk sample 
Table 8. Minimum inhibitory concentration and minimum fungicidal concentration (MIC-MFC) evidenced by Coffee husk 1 and Coffee husk 2 water and methanolic extracts on the mycotoxigenic fungi tested.

\begin{tabular}{lcccc}
\hline \multirow{2}{*}{ Fungi } & \multicolumn{2}{c}{ CH1 } & \multicolumn{2}{c}{ CH2 } \\
\cline { 2 - 5 } & MIC & MFC & MIC & MFC \\
\hline P. camemberti CECT 2267 & 25.0 & 50.0 & 25.0 & 50.0 \\
P. expansum CECT 2278 & 6.3 & 6.3 & 6.0 & 25.0 \\
P. roqueforti CECT 2905 & 12.5 & 25.0 & 12.5 & 12.5 \\
A. flavus ITEM 8111 & 25.0 & 25.0 & 50.0 & 50.0 \\
A. niger CECT 2088 & 25.0 & 50.0 & 50.0 & 50.0 \\
\hline
\end{tabular}

$\mathrm{CH}$ - Coffee Husk sample

MIC - minimum inhibitory concentration

MFC - minimum fungicidal concentration

This article is the first report on antifungal activity of the coffee husk extracts studied against the mycotoxigenic fungi, whereas many authors have studied the antimicrobial activity of other coffee components on other organisms, important in food safety. In particular coffee inhibited the growth of both Gram-positive and Gram-negative bacteria as well as of the fungus. Coffee samples were in general less active against Gram-negative bacteria than Gram-positive, with the exception of E. faecalis. The response of each microorganism to coffee samples might be influenced by a number of factors. These different activities may be attributable to structural differences in cell wall composition. Gram-negative bacteria possess a LPS component in their outer membrane that makes them more resistant to antibacterial agents. 28 Besides, bacteria susceptible to coffee are influenced by coffee variety, independently of roasting (Daglia et al., 1994). E. coli, which was inhibited by six coffee samples, is a representative of the family of Enterobacteriaceae and one of the prevalent facultative anaerobic bacteria in the intestinal tract. It is therefore used as an indicator organism for the fecal content of water and food (Campos, Couto, \& Hogg, 2003). E. faecalis was the least sensitive Gram-positive bacterium to coffee. E. faecalis is also a major member of the intestinal flora in the human body and so it is speculated that coffee does not significantly disturb the composition of gut flora. The pseudomonads are bacteria commonly found with low-temperature spoilage of foods such as meat and seafood. Under the tested conditions, coffee samples exerted a strong antibacterial effect against S. epidermidis (Li, Wang, Xu, Zhang, \& Xia, 2014). On the other hand, C. albicans is a commensal organism of the mouth and GI tract, therefore coffee may have the potential to reduce its numbers, considering that it demonstrated a great sensitivity to the powder coffee solutions. The antimicrobial activity of coffee against other bacterial species was previously studied in the literature. Various organisms have been reported, such as Streptococcus, Bacillus, other enterobacteria, or Legionella species (Lou et al., 2011). The melanoidins showed antimicrobial activity against Gram-negative reference pathogenic bacterium E. coli, and the best results were obtained with the high-molecular-weight fraction of water-soluble melanoidins (>10 kDa). At MIC value, melanoidins caused irreversible cell membrane disruption, which was independent of the bacterial trans membrane potential (Rufián-Henares \& Morales, 2008).

Antimicrobial activity of coffee depends primarily on the roasting of the coffee beans and more specifically on the roasted ingredients mediating its effects. The possible role for the microflora in the biology of the coffee plant remains enigmatic. The antibacterial properties of coffee suggest that it has a promising potential as natural food ingredient to extend and stabilize the shelf life of foods such as yoghurt, cookies, cake, or biscuits.

\section{Conclusion}

Coffee husk represents a great source of bioctive compounds showing a very high antioxidant and antimicrobial activity. This study indicates the possible exploiting of this coffee by-product as potential natural health promoting and preservative ingredient. By-products derived from the preparation of coffee for its marketing involves a great economic loss for that sector food industry. From this study, it could be concluded that there is a real possibility of using this coffee by-product for developing natural food ingredients, herbal infusions and supplements with functional properties. In future, could be interesting to evaluate the economic and enviromental impact the use of coffee husk as source of bioactive compounds

\section{Acknowledgements}

This research was supported by the Ministry of Economy and Competitiveness (AGL2016-77610R) and was also supported by the project for emerging research groups GV-2016-106 from the Generalitat Valenciana.

This research was performed under the aegis of Task Force of University of Naples Federico II "Nutraceuticals 
and Functional Food".

\section{References}

Andrade, K. S., Goncalvez, R. T., Maraschin, M., Ribeiro-do-Valle, R. M., Martínez, J., \& Ferreira, S. R. S. (2011). Supercritical fluid extraction from spent coffee grounds and coffee husks: Antioxidant activity and effect of operational variables on extract composition. Talanta, 88(15), 544-552. https://doi.org/10.1016/j.talanta.2011.11.031

Campos, F. M., Couto, J. A., \& Hogg, T. A. (2003). Influence of phenolic acids on growth and inactivation of Oenococcus oeni and Lactobacillus hilgardii. Journal of Agricultural and Food Chemistry, 94, 167-174. https://doi.org/10.1046/j.1365-2672.2003.01801.x

Castlebury, L. A., Sutherland, J. B., Tanner, L. A., Henderson, A. L., \& Cerniglia, C. E. (1999). Use of a bioassay to evaluate the toxicity of beauvericin to bacteria. World Journal of Microbiology and Biotechnology, 15, 119-121. https://doi.org/10.1023/a:1008895421989

Clifford, M. N., Johnston, K. L., Knight, S., \& Kuhnert, N. (2003). Hierarchical Scheme for LC-MSn Identification of Chlorogenic Acids. Journal of Agricultural and Food Chemistry, 51, 2900-2911. https://doi.org/10.1021/jf026187q

Daglia, M., Cuzzoni, M. T., \& Dacarro, C. (1994). Antibacterial activity of coffee. Journal of Agricultural and Food Chemistry, 42, 2270-2272. https://doi.org/10.1021/jf00046a035

Esquivel, P., \& Jiménez, V. M. (2012). Functional properties of coffee and coffee by-products. Food Research International, 46, 488-495. https://doi.org/10.1016/j.foodres.2011.05.028

Fan, L., Soccol, A. T., Pandey, A., \& Soccol, C. R. (2003). Cultivation of Pleurotus mushrooms on Brazilian coffee husk and effects of caffeine and tannic acid. Micologia Aplicada International, 15, 15-21. https://doi.org/10.1016/b978-0-12-168050-3.50031-1

Fidanza, F., \& Perriello, G. (2002). Validation of the Italian food composition database of the European institute of oncology. European Journal of Clinical Nutrition, 56, 1004-1010. https://doi.org/10.1038/sj.ejen.1601435

Franca, A. S., Gouvea, B. M., Torres, C., Oliveira, L. S., \& Oliveira, E. S. (2009). Feasibility of ethanol production from coffee husks. Biotechnology Letters, 31, 1315-1319.

https://doi.org/10.1007/s10529-009-0023-4

Heeger, A., Cagnazzo, A. K., Cantergiani, E., \& Andlauer, W. (2016). Bioactives of coffee cherry pulp and its utilisation for production of Cascara beverage. Food Chemistry, 221, 969-975.

https://doi.org/10.1016/j.foodchem.2016.11.067

International Coffee Organization (ICO). (2016). Trade statistics. http://www.ico.org/trade_statistics.asp. Last accessed [7 October 2017].

Li, G., Wang, X., Xu, Y., Zhang, B., \& Xia, X. (2014). Antimicrobial effect and mode of action of chlorogenic acid on Staphylococcus aureus. European Food Research and Technology, 238, 589-596. https://doi.org/10.1007/s00217-013-2140-5

Lou, Z., Wang, H., Zhu, S., Ma, C., \& Wang, Z. (2011). Antibacterial activity and mechanism of action of chlorogenic acid. Journal of Food Science, 76, 398-403. https://doi.org/10.1111/j.1750-3841.2011.02213.x

Ma, J. N., \& Ma, C. M. (2015). Antifungal Inhibitory Activities of Caffeic and Quinic Acid Derivatives. Coffee in Health and Disease Prevention, 635-641. https://doi.org/10.1016/b978-0-12-409517-5.00071-1

Madhyastha, M. S., Marquardt, R. R., Masi, A., Borsa, J., \& Frohllch, A. A. (1994). Comparison of toxicity of different mycotoxins to several species of bacteria and yeasts: use of Bacillus brevis in a disc diffusion assay. Journal of Food Protection, 57, 48-53. https://doi.org/10.4315/0362-028x-57.1.48

Mennini, T. (2013). Food waste and byproducts. A sustainable source of antioxidants. Nutrafoods, 12, 30-31. https://doi.org/10.1007/s13749-013-0010-1

Mullen, W., Nemzer, B., Stalmach, A., Ali, S., \& Combet, E. (2013). Polyphenolic and Hydroxycinnamate Contents of Whole Coffee Fruits from China, India, and Mexico. Journal of Agricultural and Food Chemistry, 61, 5298-5309. https://doi.org/10.1021/jf4003126

Murthy, P. S., \& Naidu, M. (2012a). Sustainable management of coffee industry by-products and value addition-A review. Resources, Conservation and Recycling, 66, 45-58. 
https://doi.org/10.1016/j.resconrec.2012.06.005

Murthy, P. S., \& Naidu, M. (2012b). Recovery of phenolic antioxidants and functional compounds from coffee industry by-products. Food and Bioprocess Technology, 5, 897-903. https://doi.org/10.1007/s11947-010-0363-z

Ning, H., Van Horn, L., Shay, C. M., \& Lloyd-Jones, D. M. (2014). Associations of Dietary Fiber Intake with Long-Term Predicted Cardiovascular Disease Risk and C-Reactive Protein Levels (from the National Health and Nutrition Examination Survey Data [2005-2010]). The American Journal of Cardiology, 113, 287-291. https://doi.org/10.1016/j.amjcard.2013.09.020

Pandey, A., Soccol, C. R., Nigam, P., Brand, D., Mohanb, R., \& Roussos S. (2000). Biotechnological potential of coffee pulp and coffee husk for bioprocesses. Biochemical Engineering Journal, 6, 153-162. https://doi.org/10.1016/s1369-703x(00)00084-x

Pèrez, M. S., Revilla, I., Gonzàlez-SanJosè, M. L., \& Beltràn, S. (1999) Various applications of liquid chromatography-mass spectrometry to the analysis of phenolic compounds. Journal of Chromatography A, 847, 75-81. https://doi.org/10.1016/s0021-9673(99)00255-1

Petersen, K. S., Flock, M. R., Richter, C. K., Mukherjea, R., Slavin, J. L., \& Kris-Etherton, P. M. (2017). Healthy dietary patterns for preventing cardiometabolic disease: the role of plant-based foods and animal products. Current Developments in Nutrition, 1(12), cdn-117. https://doi.org/10.3945/cdn.117.001289

Rabaneda, F. S., Jauregui, O., Casals, I., Andres-Lacueva C., Izquierdo-Pulido, M., \& Lamuela-Raventos, R. M. (2003). Liquid chromatographic/electrospray ionization tandem mass spectrometric study of the phenolic composition of cocoa (Theobroma cacao). Journal of Mass Spectrometry, 38, 35-42. https://doi.org/10.1002/jms.395

Rathinavelu, R., \& Graziosi, G. (2005). Potential alternative use of coffee wastes and by-products. International Coffee Organization.

Re, R., Pellegrini, N., Proteggente, A., Pannala, A., Yang, M., \& Rice-Evans C. (1999). Antioxidant activity applying an improved ABTS radical cation decolorization assay. Free Radical Biology and Medicine, 26, 1231-1237. https://doi.org/10.1016/s0891-5849(98)00315-3

Rodrigues, N. P., \& Bragagnolo, N. (2013). Identification and quantification of bioactive compounds in coffee brews by HPLC-DAD-MSn. Journal of Food Composition and Analysis, 32, 105-115. https://doi.org/10.1016/j.jfca.2013.09.002

Rufián-Henares, J. A., \& De la Cueva, S. P. (2009). Antimicrobial activity of coffee melanoidins. A study of their metal-chelating properties. Journal of Agricultural and Food Chemistry, 57, 432-438. https://doi.org/10.1021/jf8027842

Rufián-Henares, J. A., \& Morales, F. J. (2008). Antimicrobial Activity of Melanoidins against Escherichia Coli is mediated by a Membrane-Damage Mechanism. Journal of Agricultural and Food Chemistry, 56, 2357-2362. https://doi.org/10.1021/jf073300+

Siah, A., Deweer, C., Morand, E., Reignault, P., \& Halama, P. (2010). Azoxystrobin resistance of French Mycosphaerella graminicola strains assessed by four in vitro bioassays and by screening of G143A substitution. Crop Protection, 29, 737-743. https://doi.org/10.1016/j.cropro.2010.02.012

Villarino, M., Sandín-Espana, P., Melgarejo, P., \& De Cal, A. (2011). High chlorogenic and neochlorogenic acid levels in immature peaches reduce Monilinia laxa infection by interfering with fungal melanin biosynthesis. Journal of agricultural and food chemistry, 59, 3205-3213. https://doi.org/10.1021/jf104251z

Yen, G. C., \& Chen, H. Y. (1995). Antioxidant Activity of Various Tea Extracts in Relation to Their Antimutagenicity. Journal of Agricultural and Food Chemistry, 43, 27-32.

https://doi.org/10.1021/jf00049a007

\section{Copyrights}

Copyright for this article is retained by the author(s), with first publication rights granted to the journal.

This is an open-access article distributed under the terms and conditions of the Creative Commons Attribution license (http://creativecommons.org/licenses/by/4.0/). 